\title{
Editorial: realizing Brazil's potential as a world class research nation
}

\author{
Walter Leal Filho
}

Correspondence:

walter.leal@haw-hamburg.de Research and Transfer Centre, Applications of Life Sciences, Hamburg University of Applied Sciences, Faculty of Life Sciences, Ulmenliet 20, Sector S4 / Room 0.38, 21033, Hamburg, Germany
The Federative Republic of Brazil, with a population of around 200 million, is Latin America's largest country. Its territory encompasses a total of 8.514 million square kilometers, with a coastline which extends itself to nearly 7.491 kilometers, making Brazil the fifth largest nation in the world in respect of both size and population. Brazil shares a border with nearly all South American countries (the exceptions being Ecuador and Chile). The country has strong international links and relations, being one of the founding members of the United Nations, the G20, the Latin Union, the Organization of Ibero-American States, the Organization of American States, Mercosul and the Union of South American Nations, among others.

Brazil stands for the "B" of the BRIC group, which also encompasses Russia, India and China. Brazil's gross domestic product (GDP) was worth US\$2435.20 billion in 2012, representing $3.9 \%$ of the world's economy. This in turn means that Brazil has the seventh largest economy in the world, in respect of nominal GDP and purchasing power parity.

But Brazil is not only an important country due to its economic weight. The scientific potential of Brazil is significant and has historical routes: some Brazilian scientists such Alberto Santos-Dumont (aviation), Oswaldo Cruz and Carlos Chagas (biotechnology), to name only a few, are among the greatest researchers and innovators Brazil has produced. The list of distinct Brazilian researchers of international renomée is long and includes many scientific fields. The country already excels in some key areas in research and development (R\&D), for instance:

- Renewable Energy: Brazil was the first country in the world to make the nationwide use of bio-ethanol as a fuel. The process, which started in the mid 1980s, has been refined over the past decades to a great extent, making Brazil now a prime example of the use of "flexible fuels", with cars which can run on bio-ethanol, petrol or both.

- Space Research and Aviation: Brazil hosts one of the world's leading centres of aeropatial research (INPE) in and is home to Embraer, the $4^{\text {th }}$ largest airplane maker in the world.

- Health, Agriculture and Biotechnology: the country hosts world-class centres such as Fundação Oswaldo Cruz (Fiocruz) in the field of health, Butantan Institute (in biomedical research), and a leading agriculture research centre (Embrapa), among many others. The leading largest research centre on Amazon rainforest (INPA) is based in Manaus, in northern Brazil. 
This list of scientific areas and achievements is by no means comprehensive. It serves the purpose of outlining some of the many areas where Brazilian R\&D is particularly strong. More recently, the open source programming language "Lua", created by a team based in Rio de Janeiro, is now being used in Wikipedia and other major web platforms worldwide, representing a further example of the innovation potential seen in Brazil.

Brazilian R\&D, especially in the key areas outlined above, has proven to be highly efficient and this places the country in a good position to compete with industrialised nations. In some key scientific fields, the R\&D standards in Brazil are high as in North America or Europe. However, there are many problems which have hindered its further development and have been preventing Brazil from fully realising its potential as a world class research nation. Some of these barriers are:

- Economic: Brazil still invests far less in research than its competitors. In 2012, major Brazilian trade partners such as Germany, the United States and France spent $2.87 \%, 2.85 \%$ and $2.24 \%$ of their GDP in R\&D, respectively. Brazil's expenditure on R\&D in the same year, on the other hand, accounts to approximately $1.25 \%$ of its GDP. This is admittedly higher that Argentina's (0.61\%) but lower than what Mexico's spends on R\&D (1.74\%), clearly showing improvements in this field are needed.

- Infra-structure: many research centres are struggling to upkeep their infra-structure and to acquire the needed modern equipment-and facilities-, so as to meet the technology demands posed by modern research. Funding programmes to support medium to large scale research facilities, may help to mitigate this problem, and help Brazilian researchers to be able to better compete internationally.

- Limited international cooperation: even though there are various programmes at the Federal and State level which allow Brazilian researchers to study abroad (e.g. Science without Borders), there is a need to create a permanent infra-structure which attracts qualified researchers to Brazil (junior and senior), for periods of 6-12 months, or longer. The successful academic exchange programme run by the Humboldt Foundation in Germany, for instance, which attracts high caliber scientists to the country and also manages a network of Alumni, offers a good example of how well this can work. Bringing in well-established scientists to work in Brazil for periods of time, helps to complement the education of students at the host universities, boosts local/national research efforts and helps to promote the international networking of Brazilian researchers abroad.

A further problem to be overcome is related to the communication with international audiences. Most Brazilian scientists and research organisations still rely too much on publications in Portuguese, or-to a lesser extent-on Spanish or French as the means to disseminate the results of their work and projects. If the country wants to fully realize its potential, then there is a pressing need to make more use of English as a language of communication and to publish in English-language journals. This will facilitate the dissemination of results of research to a wider audience, will ensure access to international circles and foster the image of Brazil as a research-friendly country.

In order to realize its potential as a world class nation in respect of research, leading to a greater recognition and international penetration, Brazil needs to address 
the problems here raised. In terms of how to do so, three important elements may be mentioned:

- Intensification of investments in $R \& D$ and in research infra-structure, hence putting the country in a better position to compete and realize its innovation potential. The fact that Petrobras as en energy company is world famous, is partly due the substantial investments made on its research infra-structure. This has ensured its positioning as the $7^{\text {th }}$ largest energy company in the world.

- Further qualification and training of human resources in the science sector, to cater for the demands of a fast-growing nation. Brazil is a country blessed by a young population, of which over $40 \%$ is under 25 years old. More science-oriented training and careers will allow Brazil to capitalize more from the potential that scientific development offers to job creation and economic development.

- Consolidation of the research potential, by prioritizing the key areas where the country already has a good scientific standing, with parallel support to emerging fields. This combination of support to the well-established areas and assistance to new ones, will provide a fertile ground for more innovation.

The Brazilian Journal of Science and Technology (BIST) wants to provide a contribution to the development of R\&D in Brazil. It will endeavor to serve as a platform via which results of studies and research undertaken in Brazil or relevant to Brazil, are disseminated to a national and international audience. BJST should be regarded as a-timely-complement to the on-going efforts to promote Brazilian $R \& D$, being also of use to scientists from other countries in Latin American, who want to reach an international audience.

Received: 2 October 2013 Accepted: 2 October 2013

Published: 22 January 2014

doi:10.1186/2196-288X-1-1

Cite this article as: Leal Filho: Editorial: realizing Brazil's potential as a world class research nation. Brazilian Journal of Science and Technology 2013 1:1.

\section{Submit your manuscript to a SpringerOpen ${ }^{\circ}$ journal and benefit from:}

- Convenient online submission

- Rigorous peer review

- Immediate publication on acceptance

- Open access: articles freely available online

- High visibility within the field

- Retaining the copyright to your article

Submit your next manuscript at $>$ springeropen.com 